\title{
Pengaruh Habitat Sekitar Lahan Persawahan dan Umur Tanaman Padi terhadap Keanekaragaman Hymenoptera Parasitika
}

\author{
NINA HERLINA ${ }^{1), 3)}$, AKHMAD RIZALI*2),3), MOERFIAH ${ }^{1)}$, \\ BANDUNG SAHARI ${ }^{3)}$ DAN DAMAYANTI BUCHORI ${ }^{2)}$ \\ ${ }^{1)}$ Program Studi Biologi, Fakultas MIPA, Universitas Pakuan, \\ Jalan Pakuan, Bogor 16143 \\ ${ }^{2)}$ Departemen Proteksi Tanaman, Fakultas Pertanian, Institut Pertanian Bogor, \\ Kampus Darmaga, Bogor 16680 \\ ${ }^{3)}$ PEKA Indonesia Foundation, Perumahan IPB Sindang Barang II, Bogor 16610 \\ (diterima Desember 2010, disetujui Maret 2011)
}

\begin{abstract}
ABSTRAK
Pengaruh Habitat Sekitar Lahan Persawahan dan Umur Tanaman Padi terhadap Keanekaragaman Hymenoptera Parasitika. Hymenoptera Parasitika merupakan kelompok agen pengendali hayati terbesar dan memiliki peranan penting dalam mengendalikan hama di habitat pertanian. Walaupun demikian, informasi mengenai bagaimana parasitoid ini terdapat di habitat pertanian masih sangat sedikit khususnya yang berhubungan dengan kondisi habitat sekitar lahan pertanian dan fenologi dari tanaman pertanian. Tujuan dari penelitian ini adalah untuk mempelajari pengaruh habitat sekitar lahan persawahan dan umur tanaman padi terhadap keanekaragaman Hymenoptera Parasitika. Lokasi penelitian merupakan lahan persawahan yang terletak di Desa Carang Pulang, Dramaga, Bogor. Lahan persawahan dibedakan menjadi empat blok yang merepresentasikan berbagai kondisi habitat dan umur tanaman padi yang berbeda. Di setiap blok dipasang enam perangkap kuning (dengan jarak minimal 20 meter) dan satu perangkap malaise. Pengambilan contoh serangga dilakukan setiap minggu dari umur 6 hingga 12 minggu setelah tanam. Melalui penelitian ini, berhasil dikoleksi 1.833 individu Ordo Hymenoptera (tanpa semut) yang terdiri dari 9 superfamili, 23 famili, dan 216 spesies. Hymenoptera Parasitika ditemukan lebih melimpah (96\%) dan lebih beranekaragam (84\%) dibandingkan kelompok Aculeata. Kondisi habitat sekitar lahan persawahan (blok) dan umur tanaman padi berpengaruh terhadap keanekaragaman Hymenoptera Parasitika. Terdapat hubungan positif antara umur tanaman padi dengan kekayaan spesies Hymenoptera Parasitika.
\end{abstract}

KATA KUNCI: Hymenoptera parasitika, keanekaragaman, lahan persawahan, perangkap kuning, perangkap malaise

\footnotetext{
ABSTRACT

Effect of Rice Field Surrounding Habitat and Age of Rice Plant on The Diversity of Parasitic Hymenoptera. As the largest group of biological control agents, Parasitic Hymenoptera play important role in controlling pest outbreak in agricultural habitat. Unfortunately, there is lack of information *Korespondensi:

Telp.: +62-251-8425980, Faks: +62-251-8425980,

E-mail:akhmad.rizali@gmail.com
} 
about how these parasitoids occur in agricultural habitat related to condition of surrounding habitat and phenology of crop plant. The objective of this research was to study the effect of rice field surrounding habitat and age of rice plant on the diversity of Parasitic Hymenoptera. Research area was located in Carang Pulang Village, Dramaga, Bogor. We selected four blocks which represented different of habitat condition and age of rice plant. Each block was set six yellow pan traps (with minimum distance 20 meter) and one malaise trap. Sampling of insects were conducted weekly from 6 to 12 week after planting. From this research, we collected 1,833 individual of Hymenoptera (without ants) belong to 9 superfamilies, 23 families, and 216 species. Parasitic Hymenoptera was more abundant (96\%) and species rich (84\%) than Aculeata. Rice field surrounding habitat (block) and age of rice field significantly affect the diversity of Parasitic Hymenoptera. We found positively correlation between age of rice plant and species richness of Parasitic Hymenoptera.

KEY WORDS: Parasitic Hymenoptera, diversity, rice field, yellow pan trap, malaise trap

\section{PENDAHULUAN}

Keberadaan musuh alami pada ekosistem pertanian, baik itu predator maupun parasitoid, memiliki peranan yang sangat penting khususnya dalam pengaturan populasi serangga hama (Altieri 1999). Penggunaan pestisida untuk mengendalikan serangga hama, cenderung mengakibatkan penurunan atau bahkan menghilangkan keberadaan musuh alami (Wanger et al. 2010). Oleh karena itu upaya konservasi seperti manajemen habitat lahan pertanian, menjadi sangat penting dilakukan untuk mempertahankan keberadaan musuh alami tersebut (Perfecto et al. 2009).

Pada sistem pertanian sawah, keberadaan musuh alami dapat dipengaruhi oleh kondisi habitat sekitarnya dan juga fase pertumbuhan tanaman padi. Habitat sekitar lahan persawahan yang berupa hutan, dapat mendukung keberadaan musuh alami yaitu sebagai habitat alternatif dan penyedia sumber makanan (Rizali et al. 2002). Fase pertumbuhan tanaman padi yang berbeda menyebabkan keberadaan musuh alami juga berbeda untuk tiap fasenya. Hal ini karena hama yang merupakan inang dari musuh alami, berbeda jenisnya pada setiap fase baik vegetatif maupun fase generatif (Heinrichs et al. 1994).

Diantara musuh alami yang berperan penting dalam mengendalikan populasi hama adalah parasitoid. Ordo Hymenoptera merupakan ordo serangga yang memiliki paling banyak kelompok parasitoid (grup parasitika) disamping kelompok yang lain seperti herbivor, predator, dan polinator (grup Aculeata) (Goutlet \& Huber 1993). Parasitoid khususnya parasitoid telur dapat mengendalikan hama sebelum hama itu sempat merusak (Heinrichs et al. 1994). Oleh karenanya, parasitoid dianggap sangat efektif untuk mengen- 
dalikan populasi hama pada lahan pertanian (Altieri 1999).

Masih sedikitnya informasi mengenai keanekaragaman parasitoid pada lahan pertanian dalam hubungannya dengan kondisi habitat dan fenologi tanaman, menyebabkan parasitoid belum dapat dimanfaatkan secara optimal. Penelitian ini bertujuan untuk mempelajari keanekaragaman Hymenoptera parasitika pada habitat sekitar lahan persawahan dan perbedaan umur tanaman padi.

\section{BAHAN DAN METODE}

Penelitian dilakukan pada area persawahan yang terletak di Desa Carang Pulang, Dramaga, Bogor. Landskap pertanian daerah ini tergolong kompleks. Selain tanaman padi (sebagai tanaman pertanian utama) juga terdapat tanaman pertanian lain dan dikelilingi oleh hutan sekunder, semak, dan sungai. Sistem pertanian yang ada pada setiap petak lahan berbeda bergantung pada pemilik lahan. Beberapa pemilik lahan melakukan pengisian tanaman dengan tanaman pertanian lain seperti jagung, ubi, tanaman palawija, dan tanaman lain. Hal tersebut menyebabkan umur tanaman padi pada area ini tidak seragam karena antar pemilik lahan menentukan waktu tanam yang berbeda.

Blok penelitian ditentukan berdasarkan kesamaan umur tanaman padi dan kondisi habitat sekitar blok (Gambar 1). Oleh karena umur tanaman padi yang bervariasi, landskap pertanian dibagi menjadi empat blok dimana setiap blok memiliki umur tanaman padi yang seragam. Pada setiap blok, ditentukan enam titik (dengan jarak minimal antar titik 20 meter) untuk pemasangan perangkap kuning (yellow pan trap) dan satu titik untuk perangkap malaise (malaise trap). Perangkap kuning dan perangkap malaise merupakan perangkap yang efektif untuk mengoleksi serangga Ordo Hymenoptera (Noyes 1994). Kedua perangkap tersebut dipasang selama 24 jam, untuk kemudian dikoleksi serangga yang terperangkap di dalamnya. Pengambilan contoh serangga pada setiap blok dilakukan setiap minggu antara umur tanaman padi 6 hingga 12 minggu setelah tanam (MST). Waktu pengambilan contoh serangga ini dilaksanakan antara bulan Juli hingga Oktober 2007.

Seluruh spesimen yang diperoleh dari perangkap disimpan dalam botol plastik berisi alkohol $70 \%$ untuk selanjutnya dilakukan pemilihan dan identifikasi di laboratorium. Spesimen dipilih berdasarkan perbedaan taksa dan untuk Ordo Hymenoptera dilaku kan identifikasi hingga tingkat famili untuk kemudian dilakukan pembedaan jenis spesies berdasarkan morfospesies famili. Identifikasi Ordo Hymenoptera hingga tingkat famili dilakukan berdasarkan buku acuan yang ada (Boucek 1988; Goutlet \& Huber 1993; Fitton \& Day 1994; Heinrichs et al. 1994; Borror et al. 1996). 


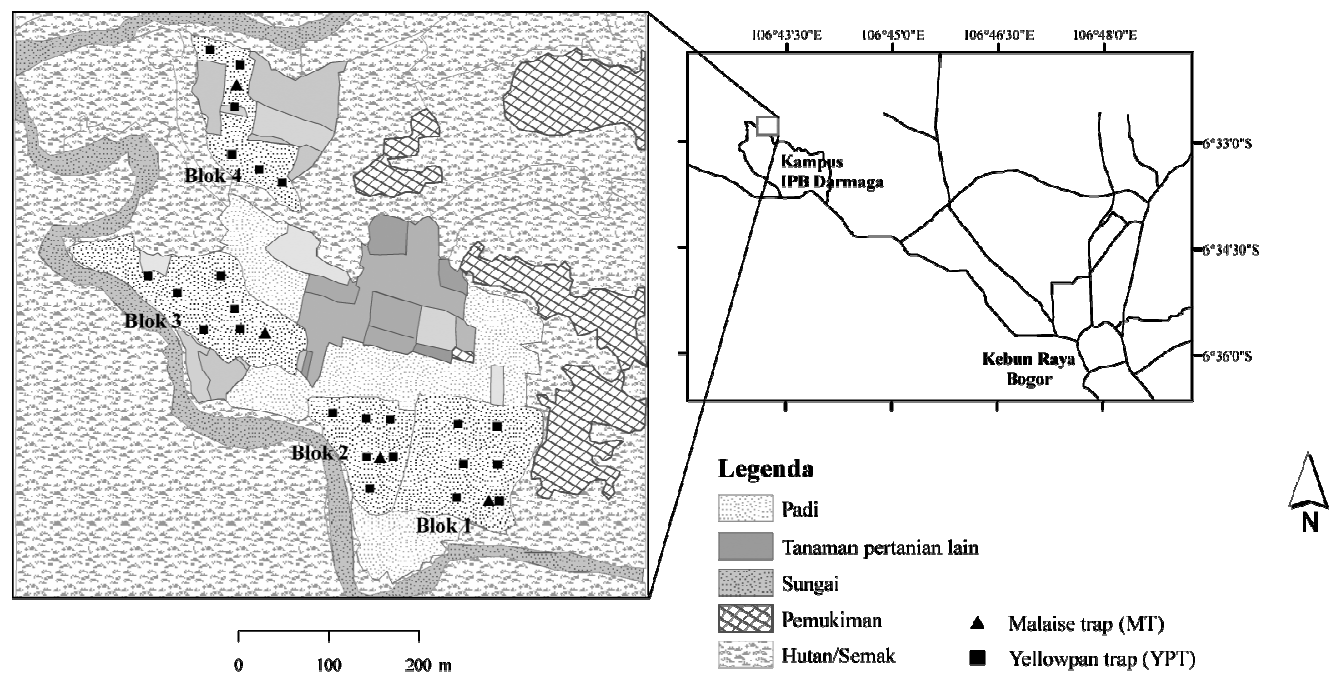

Gambar 1. Lanskap area pertanian di Desa Carang Pulang, Dramaga, Bogor. Area penelitian dikategorikan ke dalam empat blok (Blok 1-4), dimana setiap blok memiliki kondisi habitat sekitar yang berbeda

Analisis ragam (analisi of variance, ANOVA) digunakan untuk melihat perbedaan keanekaragaman spesies Hymenoptera Parasitika antar blok dan umur tanaman padi yang berbeda. Sedangkan model linier (linear model, LM) digunakan untuk melihat hubungan umur tanaman padi dengan keanekaragaman spesies Hymenoptera parasitika. Keseluruhan analisis tersebut dilakukan dengan menggunakan perangkat lunak $R$ Statistic (R Development Core Team 2011).

\section{HASIL DAN PEMBAHASAN}

\section{Keanekaragaman Hymenoptera} Parasitika pada Pertanaman Padi di Dramaga, Bogor

Berdasarkan hasil tangkapan perangkap kuning dan perangkap malaise antara umur padi 6 hingga 12 MST pada persawahan di Dramaga, Bogor, diperoleh 1.833 individu Ordo Hymenoptera (selain semut) yang termasuk ke dalam 9 superfamili, 23 famili, dan 216 spesies (Tabel 1). Hymenoptera parasitika ditemukan lebih banyak dibandingkan dengan Aculeata, baik dari kelimpahan individu (1.763 individu, 96\%) maupun kekayaan spesiesnya (182 spesies, 84\%) (Tabel 1 dan Tabel 2).

Famili-famili dari kelompok Hymenoptera parasitika yang ditemukan umumnya merupakan parasitoid telur (Table 2). Famili Scelionidae ditemukan paling banyak variasi jenis spesies (19\%) dan jumlah individunya (33\%) dibandingkan dengan famili yang lain. 
Tabel 1. Keanekaragaman Ordo Hymenoptera (selain semut) pada setiap blok di persawahan (total pengamatan dari umur tanaman padi 6 - 12 MST) di Dramaga, Bogor.

\begin{tabular}{|c|c|c|c|c|c|c|c|c|c|c|}
\hline \multirow{2}{*}{ Grup } & \multicolumn{5}{|c|}{ Perangkap kuning } & \multicolumn{5}{|c|}{ Perangkap malaise } \\
\hline & 1 & 2 & 3 & 4 & Total & 1 & 2 & 3 & 4 & Total \\
\hline \multicolumn{11}{|l|}{ ACULEATA } \\
\hline Subfamili & 1 & 1 & 2 & 2 & 3 & 2 & 2 & 2 & 3 & 3 \\
\hline Famili & 1 & 1 & 2 & 2 & 4 & 6 & 4 & 2 & 7 & 8 \\
\hline Spesies & 1 & 1 & 2 & 3 & 6 & 15 & 8 & 4 & 15 & 32 \\
\hline Individu & 1 & 2 & 2 & 6 & 11 & 20 & 11 & 4 & 24 & 59 \\
\hline \multicolumn{11}{|l|}{ PARASITIKA } \\
\hline Subfamili & 5 & 5 & 5 & 6 & 6 & 6 & 5 & 5 & 5 & 6 \\
\hline Famili & 11 & 13 & 14 & 12 & 16 & 14 & 14 & 12 & 11 & 15 \\
\hline Spesies & 70 & 81 & 67 & 66 & 128 & 75 & 82 & 62 & 45 & 137 \\
\hline Individu & 199 & 357 & 197 & 227 & 980 & 226 & 271 & 171 & 115 & 783 \\
\hline
\end{tabular}

Tabel 2. Jumlah individu (N), spesies (S), dan peranan setiap famili (berdasarkan Borror et al. (1996) dan Goutlet \& Huber (1993)) dari Hymenoptera Parasitika di Dramaga, Bogor.

\begin{tabular}{lrrl}
\hline \hline No $\quad$ Famili & $\mathrm{S}$ & $\mathrm{N}$ & Peranan \\
\hline Cerapronoidea & & & \\
1. Cerapronidae & 14 & 99 & Parasitoid Imago \\
Chalcidoidea & & & \\
2. Aphelinidae & 1 & 1 & Parasitoid Telur, Pupa,dan Imago \\
3. Chalcididae & 9 & 20 & Parasitoid, Telur, Larva, Pupa, dan Imago \\
4. Elasmidae & 6 & 55 & Parasitoid Larva \& Imago \\
5. Encyrtidae & 17 & 97 & Parasitoid Telur \& Nimfa \\
6. Eulophidae & 23 & 143 & Parasitoid Telur \& Larva \\
7. Mymariidae & 10 & 94 & Parasitoid Telur \\
8. Mymarommatidae & 1 & 2 & Peranan Belum diketahui \\
9. Pteromalidae & 9 & 91 & Parasitoid Telur \\
10 Trichogrammatidae & 5 & 28 & Parasitoid Telur \\
Evanoidea & & & \\
11. Evaniidae & 5 & 5 & Parasitoid Telur \& Pupa \\
Ichneumonoidea & & & \\
12. Braconidae & 14 & 153 & Parasitoid Larva \& Telur \\
13. Ichneumonidae & 13 & 29 & Parasitoid Larva \& Telur \\
Platygastroidea & & & \\
14. Platygastriidae & 4 & 38 & Parasitoid Telur \& Larva \\
15. Scelionidae & 34 & 586 & Parasitoid Telur \\
Proctotrupoidea & & & \\
16. Diapriidae & 17 & 322 & Parasitoid Telur \& Imago \\
$\quad$ Total & 182 & 1.763 & \\
\hline
\end{tabular}


Pengaruh Kondisi Habitat Sekitar Lahan Persawahan dan Perbedaan Umur Tanaman Padi terhadap Keanekaragaman Hymenoptera Parasitika

Hasil uji ANOVA menunjukkan bahwa kondisi habitat sekitar lahan (blok) dan umur tanaman padi berpengaruh terhadap keanekaragaman Hymenoptera Parasitika (Tabel 3). Berdasarkan data dari perangkap kuning, keanekaragaman Hymenoptera Parasitika dipengaruhi secara nyata oleh blok dan umur tanaman padi, sedangkan data dari perangkap malaise tidak menunjukkan perbedaan yang nyata. Walaupun demikian secara keseluruhan, posisi lahan menunjukkan pengaruh yang nyata terhadap keanekaragaman Hymenoptera Parasitika pada persawahan di Dramaga, Bogor (Tabel 3, $\mathrm{F}_{3,18}=4,299 ; \mathrm{P}=0,019$ ).

Berdasarkan model linier menunjukkan bahwa terdapat korelasi positif (Gambar 2) antara umur tanaman padi dengan keanekaragaman Hymenoptera Parasitika khususnya berdasarkan data dari perangkap kuning $\left(\mathrm{F}_{1,26}=21,09\right.$; $\left.\mathrm{P}<0,000 ; \mathrm{r}^{2}=0,427\right)$ dan total perangkap $\left(\mathrm{F}_{1,26}=6,443 ; \mathrm{P}=0,017 ; \mathrm{r}^{2}=0,168\right)$. Korelasi tersebut terlihat cukup nyata pada blok 1 dan blok 2 (Gambar 3 dan Gambar 4) .

Penggunaan perangkap yang berbeda memberikan informasi yang lengkap mengenai keanekaragaman Ordo Hymenoptera pada persawahan di Dramaga, Bogor.

Tabel 3. Perbedaan keanekaragaman Hymenoptera Parasitika berdasarkan perangkap yang berbeda pada kondisi lahan/blok dan umur tanaman padi yang berbeda

\begin{tabular}{lrrc}
\hline Faktor & Perangkap Kuning & Perangkap Malaise & Total \\
\hline Blok & $\mathrm{F}_{3,18}=3,318 ; \mathrm{P}=0,043$ & $\mathrm{~F}_{3,18}=2,903 ; \mathrm{P}=0,063$ & $\mathrm{~F}_{3,18}=4,299 ; \mathrm{P}=0,019$ \\
Umur & $\mathrm{F}_{6,18}=5,417 ; \mathrm{P}=0,002$ & $\mathrm{~F}_{6,18}=0,486 ; \mathrm{P}=0,810$ & $\mathrm{~F}_{6,18}=1,547 ; \mathrm{P}=0,219$ \\
\hline
\end{tabular}

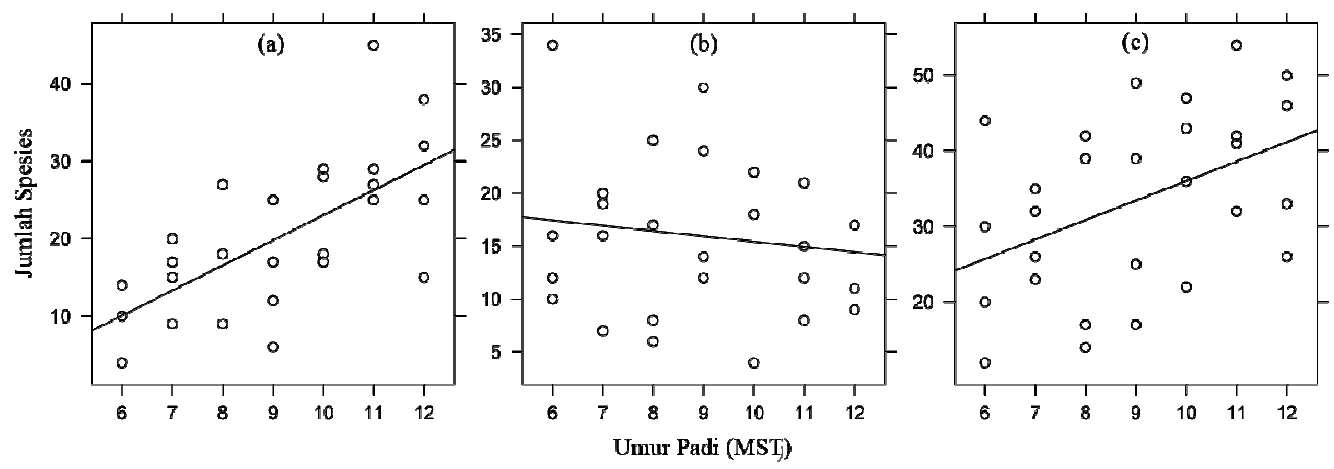

Gambar 2. Hubungan kekayaan spesies Hymenoptera Parasitika dengan umur tanaman padi pada persawahan di Dramaga, Bogor. (a) berdasarkan perangkap kuning $\left(\mathrm{F}_{1,26}=21,09 ; \mathrm{P}<0,000 ; \mathrm{r}^{2}=0,427\right)$, (b) perangkap malaise $\left(\mathrm{F}_{1,26}=0,527 ; \mathrm{P}=0,474 ; \mathrm{r}^{2}=-0,018\right)$, dan $(\mathrm{c})$ total keseluruhan perangkap $\left(\mathrm{F}_{1,26}=6,443 ; \mathrm{P}=0,017 ; \mathrm{r}^{2}=0,168\right)$ 


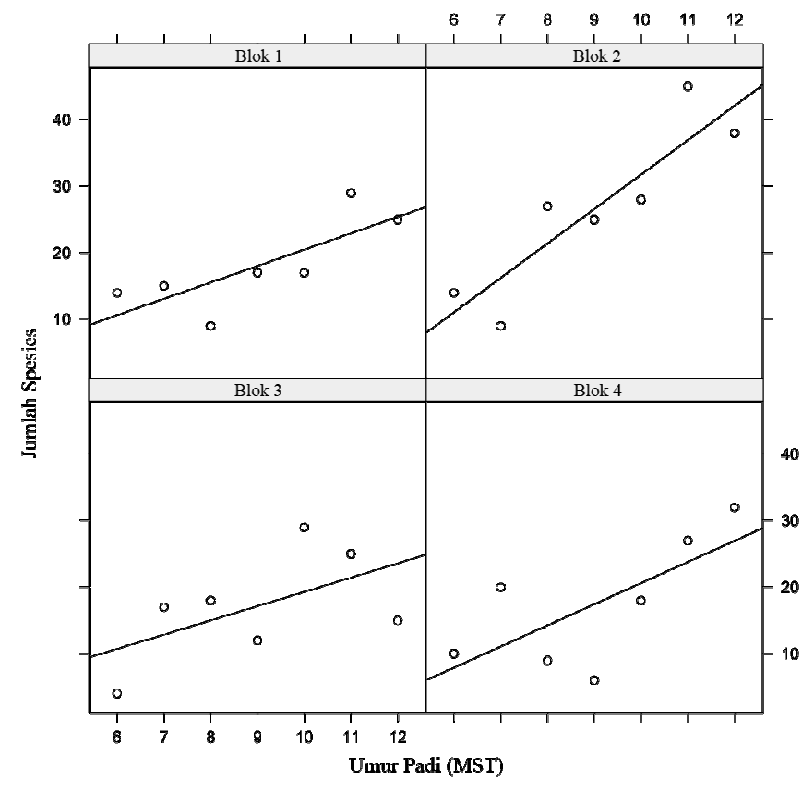

Gambar 3. Hubungan kekayaan spesies Hymenoptera Parasitika dengan umur tanaman padi (MST) berdasarkan hasil koleksi dengan menggunakan perangkap kuning pada setiap blok pengamatan (Blok 1, $\mathrm{t}=5,156$, $\mathrm{P}<0,000$; Blok 2, $\mathrm{t}=2,411, \mathrm{P}=0,024$; Blok 3, $\mathrm{t}=-0,241, \mathrm{P}=0,812$; Blok $4, \mathrm{t}=-0,161, \mathrm{P}=0,874$ )

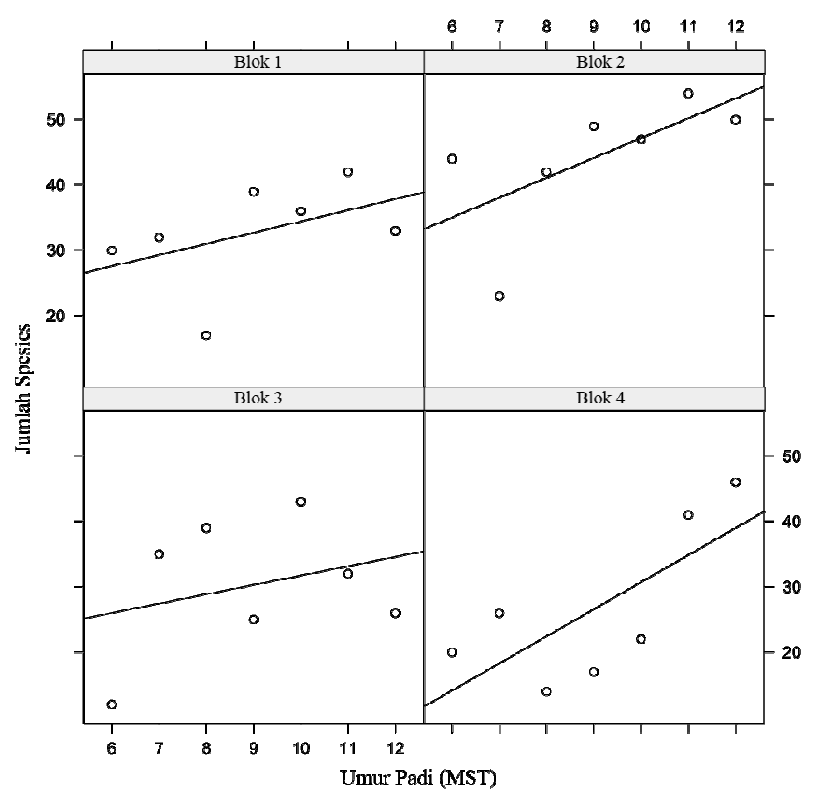

Gambar 4. Hubungan kekayaan spesies Hymenoptera Parasitika dengan umur tanaman padi (MST) berdasarkan hasil koleksi dengan menggunakan keseluruhan perangkap pada setiap blok pengamatan (Blok 1, $\mathrm{t}=3,084$, $\mathrm{P}=0,005$; Blok 2, $\mathrm{t}=2,414, \mathrm{P}=0,024$; Blok 3, $\mathrm{t}=-0,513, \mathrm{P}=0,613$; Blok $4, \mathrm{t}=-1,298, \mathrm{P}=0,207$ ) 
Keanekaragaman Ordo Hymenoptera (selain semut) lebih didominasi oleh kelompok parasitika dibandingkan dengan Aculeata. Hymenoptera Aculeata sebagian besar terkoleksi dengan menggunakan perangkap malaise. Hal tersebut menunjukkan bahwa Hymenoptera Aculeata habitat utamanya bukan di persawahan, tapi di sekitar lahan persawahan dimana serangga tersebut aktif terbang melintasi persawahan untuk mencari nektar.

Perbedaan respon keanekaragaman Hymenoptera Parasitika antar perangkap (perangkap kuning dan perangkap malaise) terhadap kondisi habitat sekitar lahan (blok) dan umur tanaman padi, mengindikasikan bahwa masing-masing perangkap merepresentasikan keanekaragaman pada skala habitat tertentu. Perangkap kuning dalam hal ini lebih merepresentasikan Hymenoptera Parasitika pada skala tanaman padi, sedangkan perangkap malaise merepresentasikan keanekaragaman Hymenoptera Parasitika pada tingkat lahan.

Terdapatnya perbedaan keanekaragaman Hymenoptera Parasitika antar blok menunjukkan bahwa kondisi habitat sekitar lahan persawahan mempengaruhi keanekaragaman Hymenoptera Parasitika yang ada di dalamnya. Hal tersebut sama dengan hasil penelitian sebelumnya yang menemukan bahwa habitat sekitar lahan persawahan mempengaruhi keanekaragaman serangga termasuk musuh alami (Settle et al. 1996; Rizali et al. 2002). Selain itu, adanya korelasi positif antara umur tanaman padi dengan keanekaragaman Hymenoptera Parasitika, mengindikasikan bahwa keanekaragaman parasitoid cenderung meningkat dengan bertambahnya umur padi. Pada kondisi habitat yang mendukung, keanekaragaman parasitoid mengikuti keanekaragaman inangnya yang berbeda di setiap fase pertumbuhan tanaman padi (Heinrichs et al. 1994). Adanya hubungan keanekaragaman parasitoid dengan keanekaragaman inang menjadikan parasitoid dapat digunakan sebagai bioindikator untuk melihat perubahan keanekaragaman arthropoda termasuk hama di lahan pertanian (Anderson et al. 2011). Hal ini menunjukkan bahwa lahan persawahan di Dramaga, dengan kondisi habitat yang heterogen, memiliki agen pengendali hayati (parasitoid) yang cukup untuk menekan populasi hama.

Keanekaragaman Hymenoptera Parasitika yang ada pada lahan persawahan tidak hanya dipengaruhi oleh kondisi habitat sekitar maupun umur tanaman padi. Menurut penelitian Hamid et al. (2003), musim yang berbeda juga dapat mempengaruhi keanekaragaman parasitoid di lahan persawahan. Walaupun demikian, kondisi habitat sekitar diduga merupakan faktor utama yang menyebabkan perbedaan keanekaragaman Hymenoptera $\mathrm{Pa}$ rasitika yang ada di lahan persawahan. Kondisi habitat sekitar lahan dapat 
mempengaruhi jejaring makanan (food $w e b)$ antara parasitoid dengan inangnya (Tylianakis et al. 2007; Laliberté \& Tylianakis 2010) dan keberadaan serta distribusi dari parasitoid (Elzinga et al. 2007).

\section{KESIMPULAN}

Habitat sekitar lahan persawahan dan umur tanaman padi mempengaruhi keanekaragaman Hymenoptera Parasitika yang ada di dalamnya. Walaupun demikian, kondisi habitat sekitar lahan merupakan faktor utama yang menyebabkan perbedaan keanekaragaman parasitoid. Oleh karena itu, majemen habitat sekitar lahan pertanian merupakan hal yang sangat penting untuk dilakukan sebagai upaya konservasi parasitoid pada lahan pertanian.

\section{UCAPAN TERIMAKASIH}

Penelitian ini dibiayai oleh SEARCA Seed Fund for Research and Training (SFRT). Terimakasih kepada Enri Agus Setiani dan Iyus Rahman yang telah membantu selama pengambilan contoh di lapangan.

\section{DAFTAR PUSTAKA}

Altieri MA. 1999. The ecological role of biodiversity in agroecosystems. Agriculture Ecosystems \& Environment 74:19-31.

Anderson A, McCormack S, Helden A, Sheridan H, Kinsella A, Purvis G. 2011. The potential of parasitoid Hymenoptera as bioindicators of arthropod diversity in agricultural grasslands. Journal of Applied Ecology 48:382-390.

Borror D, Triplehorn CH, Johnson NF. 1996. An Introduction to The Study of Insects 6th Edition. Ohio, USA: Saunders College Publishing.

Boucek Z. 1988. An Overview of the Higher Classification of the Chalcidoidea (Parasitic Hymenoptera). In: Gupta VK (Ed.), Advances in Parasitic Hymenoptera Research. Leiden, The Netherlands: E.J. Brill. p 716.

Elzinga JA, van Nouhuys S, van Leeuwen D-J, Biere A. 2007. Distribution and colonisation ability of three parasitoids and their herbivorous host in a fragmented landscape. Basic and Applied Ecology. 8:75-88.

Fitton MG, Day MC. 1994. Taxonomy and Biology of Parasitic Hymenoptera. London, UK: Departement of Entomology, The Natural History Museum.

Goutlet H, Huber JT. 1993. Hymenoptera of the World : an Identification Guide to Families. Ottawa, Canada: Centre for Land and Biological Resources Research.

Hamid H, Buchori D, Triwidodo H. 2003. Keanekaragaman parasitoid dan parasitisasinya pada pertanaman padi di kawasan Taman Nasional Gunung Halimun. HAYATI Journal of Biosciences 10:85-90.

Heinrichs EA, Aguda RM, Barrion AT, Bharathi M, Chelliah S, Dalle D, Gallagher K O, Kritani $\mathrm{K}$, Litsinger J A, Loevinsohn M E, Naba K, Ooi PAC, O.Parada, 
Roberts D W, Rombach M C, Shepard BM, Smith CM, Weber G. 1994. Biology and Management of Rice Insects. New Delhi, India: International Rice Research Institute - Willey Eastern.

Laliberté E, Tylianakis JM. 2010. Deforestation homogenizes tropical parasitoid-host networks. Ecology 91:1740-1747.

Noyes JS. 1994. A study of five methods of sampling Hymenoptera (insecta) in a tropical rainforest, with special reference to the parasitica. $J$ Nat Hist. 23:285-298.

Perfecto I, Vandermeer JH, Wright AL. 2009. Nature's matrix: linking agriculture, conservation and food sovereignty. London: Earthscan.

R Development Core Team. 2011. R: A language and environment for statistical computing. R Foundation for Statistical Computing, Vienna, Austria.
Rizali A, Buchori D, Triwidodo $\mathrm{H}$. 2002. Keanekaragaman serangga pada lahan persawahan-tepian hutan: indikator untuk kesehatan lingkungan. HAYATI Journal of Biosciences 9:41-48.

Settle WH, Ariawan H, Astuti E T, Cahyana W, Hakim A L, Hindayana D, Lestari A S, Pajarningsih, Sartanto. 1996. Managing tropical rice pests through conservation of generalist natural enemies and alternative prey. Ecology 77: 19751988.

Tylianakis JM, Tscharntke T, Lewis OT. 2007. Habitat modification alters the structure of tropical host-parasitoid food webs. Nature 445:202-205.

Wanger TC, Rauf A, Schwarze S. 2010. Pesticides and tropical biodiversity. Frontiers in Ecology and the Environment 8:178179. 